\title{
Ampulla of Vater Intestinal-Type Adenoma
}

National Cancer Institute

\section{Source}

National Cancer Institute. Ampulla of Vater Intestinal-Type Adenoma. NCI Thesaurus.

Code C6657.

An adenoma that arises from the ampulla of Vater and resembles the adenomas of the small and large intestines. Morphologically, according to the growth pattern, it may be classified as tubular, tubulovillous, or villous. Dysplasia is always present. Jaundice may be an early symptom. 